\title{
JARAK KEKUASAAN SEBAGAI PEMODERASI PENGARUH KEADILAN ORGANISASIONAL TERHADAP KOMITMEN KARYAWAN PADA SUPERVISOR (Studi pada Sebuah Perusahaan Batik di Surakarta)
}

\author{
Hunik Sri Runing (hunik_sri@yahoo.co.id) \\ Fakultas Ekonomi Universitas Sebelas Maret Surakarta
}

\begin{abstract}
This research was conducted to analyze 1) influence of procedural and distributive justice to employee commitment to supervisor, 2) moderation role of the power distance orientation to the influence of procedural and distributive justice to employee commitment to supervisor. Hypothesis testing was using moderated regression analysis. Using 150 samples, the result indicates that 1) procedural and distributive justice has a significant effect on employee commitment to supervisor, 2) power distance orientation moderates the influence of procedural and distributive justice to employee commitment to supervisor.
\end{abstract}

Keywords: Power Distance, Procedural Justice, Distributive Justice, Employee Commitment to Supervisor.

\section{PENDAHULUAN}

Supervisor merupakani foci komitmen terpenting bagi karyawan (Chen, Tsui, \& Farh 2002). Bertindak sebagai agen organisasi, supervisor sering berinteraksi dengan karyawan seharihari, terlibat dalam prosedur aktivitas terorganisasi secara formal maupun informal, dan yang paling penting bertindak sebagai pengatur imbalan bagi bawahannya (Farh, Podsakof, \& Organ dalam Chen et al., 2002).

Sejalan dengan pentingnya supervisor sebagai foci komitmen, konsep komitmen pada supervisor mendapat perhatian besar dari peneliti beberapa tahun terakhir (Wong, Wong, \& Ngo, 2002). Berbeda dengan komitmen pada organisasi yang telah menjadi perhatian sejak tahun 1950-an, penelitian tentang komitmen pada supervisor baru berkembang akhir-akhir ini (Becker, 1992; Becker et al., 1996; Gregersen, dalam Chen et al., 2002). Itu pun sebagian besar penelitian dilakukan di Negara Barat.

Penelitian yang telah dilakukan menunjukkan hasil tentang pentingnya foci komitmen ini sebagai prediktor kinerja tugas (Becker, 1992; Becker, 1996; Becker et al., 1996; Chen et al., 2002). Dibanding dengan komitmen pada organisasi, komitmen pada supervisor ini merupakan prediktor yang lebih baik dan lebih kuat terhadap kinerja tugas (Becker et al., 1996; Chen et al., 2002; Sawitri \& Karsono, 2006).

Selama ini penelitian yang berkaitan dengan faktor-faktor yang mempengaruhi komitmen pada supervisor masih relatif terbatas. Bahkan Wong, Wong, \& Ngo (2002) secara ekesplisit menyatakan bahwa penelitian tentang anteseden komitmen pada supervisor belum pernah dilakukan. Oleh karena itu sangat terbuka lebar kesempatan untuk melakukan penelitian yang menyelidiki tentang faktor-faktor yang memengaruhi komitmen karyawan pada supervisor.

Penelitian ini merupakan pengembangan dari penelitian sebelumnya yang berjudul "Komitmen Karyawan pada Organisasi dan Komitmen Karyawan pada Supervisor: Implikasinya pada Kinerja" (Sawitri \& Karsono, 2006). Temuan hasil penelitian itu mendukung temuan sebelumnya, yaitu bahwa komitmen pada supervisor mempunyai hubungan lebih kuat dengan kinerja tugas dibanding komitmen pada organisasi. Temuan hasil yang demikian, mendorong dilakukannya penelitian lanjutan mengenai faktor-faktor yang 
berkaitan dengan komitmen pada supervisor. Artinya dengan lebih kuatnya hubungan antara komitmen pada supervisor dan kinerja, maka perlu bagi perusahaan melakukan upaya agar komitmen karyawan pada supervisor dapat terpelihara dan/atau menjadi lebih meningkat yang kemudian mengarah pada kinerja yang lebih baik, yaitu dengan menggali lebih lanjut faktor-faktor yang berkaitan dengan komitmen pada supervisor.

Penelitian ini bermaksud mengaitkan keadilan organisasional (prosedural dan distributif) dan komitmen karyawan pada supervisor dengan jarak kekuasaan sebagai variabel pemoderasi. Keadilan prosedural adalah derajat keadilan yang dipersepsikan terhadap prosedur yang digunakan untuk mendistribusi, sedangkan keadilan distributif adalah derajat keadilan yang dipersepsikan dalam mendistribusi sumberdaya dan imbalan organisasi. Dengan perkataan lain, keadilan prosedural berkaitan dengan persepsi karyawan terhadap kebijakan dan prosedur yang digunakan dalam menentukan outcome, sedangkan keadilan distributif berkaitan dengan persepsi karyawan terhadap outcome yang diterima (Skarlicki \& Folger, 1997; Colquitt, 2001).

Hasil penelitian yang lalu mengenai keadilan menunjukkan bahwa persepsi karyawan tentang keadilan mempunyai dampak yang kuat pada evaluasinya terhadap atasan (supervisor) tempat mereka bekerja. Karyawan yang mempunyai persepsi diperlakukan secara adil cenderung mengevaluasi atasannya lebih baik (Lee, Pillutla, \& Law, 2000). Penelitian yang lalu juga menunjukkan bahwa keadilan mempunyai hubungan positif dengan komitmen (Tang \& Sarsfield-Baldwin, 1996).

Kemudian jarak kekuasaan mengacu pada konsepsi kultural berkaitan dengan sejauh mana orang berharap dan menerima bahwa kekuasaan dalam organisasi terdistribusi secara tidak merata antara superior dan bawahannya (Hofstede dalam Yang, Peng, \& Mossholder, 2004). Individu dengan orientasi jarak kekuasaan tinggi cenderung lebih bersedia menerima perbedaan status. Oleh karena itu, individu dalam posisi status rendah tidak akan mempertanyakan wewenang individu pada level yang lebih tinggi dalam organisasi (Yang et al., 2004).

Jarak kekuasaan dipilih dalam penelitian ini karena berkaitan dengan pendapat individu tentang apa yang dapat diterima dalam hubungan atasan-bawahan, sehingga faktor ini relevan untuk menyelidiki peran persepsi keadilan dalam mengevaluasi atasan. Perbedaan dalam jarak kekuasaan akan memengaruhi pentingnya keadilan bagi karyawan dalam mengevaluasi atasannya (Lee et al., 2000), karena keyakinan kultural akan menentukan pentingnya keadilan bagi individu (Yang et al., 2004). Ini berarti, bagi sebagian besar orang, tidak selalu memandang keadilan sebagai sinyal untuk menunjukkan pertukaran sosial (misalnya, berusaha lebih keras untuk organisasi), dan tidak juga memandang sebagai cara bahwa bawahan merasa wajib mengganti kenikmatan yang telah dirasakan. Oleh karena itu, bagaimana persepsi keadilan dievaluasi oleh bawahan akan memengaruhi besaran dampak dari keadilan ini. Dengan perkataan lain, keyakinan normatif individu tentang keadilan akan bervariasi menurut nilai-nilai kultural yang dianut (Tyler \& McGraw, 1986).

Berdasarkan uraian tersebut, secara singkat dapat dikatakan bahwa organisasi yang ingin mempertahankan atau meningkatkan komitmen pada supervisornya perlu memahami persepsi keadilan yang dirasakan oleh bawahannya yang dapat memengaruhi komitmennya pada supervisor, dan bahwa pengaruh itu tergantung pada jarak kekuasaan yang dirasakannya.

Perusahaan Batik ini merupakan perusahaan besar yang mempunyai banyak karyawan tidak lepas perhatiannya terhadap keadilan yang dirasakan oleh para karyawannya. Dengan kepeduliannya pada keadilan ini diharapkan akan memberi pengaruh positif pada komitmen karyawan pada supervisornya, yang pada gilirannya akan mampu meningkatkan kinerja.

\section{TINJAUAN PUSTAKA DAN PENGEMBANGAN HIPOTESIS}


Komitmen dan Foci Komitmen

Komitmen pada organisasi dapat dijelaskan melalui berbagai pendekatan (Suliman \& lles, 2000). Pendekatan kesikapan merupakan pendekatan paling terkenal untuk mengkonseptualisasikan komitmen organisasional. Pendekatan ini disampaikan oleh Porter et al. (1974). Menurut pendekatan ini, komitmen organisasional didefinisikan sebagai "kekuatan relatif identifikasi dan keterlibatan individual dalam organisasi tertentu." Individu yang mengidentifikasi organisasi, kemudian berkomitmen untuk memelihara keanggotaannya untuk mengikuti tujuannya (McGee \& Ford, 1987).

Perkembangan selanjutnya tentang konsep komitmen, mengarahkan pada pentingnya membedakan antara motif (bases) dan target (foci) ganda komitmen (Becker, 1992; Becker et al., 1986; Meyer, Paunonen, Gellaty, Goffin, \& Jackson, 1989; Reichers, 1986; Somers \& Birnbaum, 1998; Becker \& Kernan, 2003; Bishop \& Scott, 1996). Target komitmen adalah individual dan kelompok yang karyawan terikat (Reichers, 1985), sementara motif komitmen mengacu pada motif yang mendasari keterikatan (Becker, 1992; O’Reilly \& Chatman dalam Becker et al., 1996)).

Berkaitan dengan target komitmen, kecuali organisasi target-target komitmen lain dianjurkan, seperti pekerjaan, manajemen puncak, teman sekerja, unit kerja dan kustomer, serikat pekerja, supervisor, dan/atau publik secara umum (Becker, 1992; Becker et al., 1996; Reichers, 1985; Meyer et al., 1993; Chen et al., 2002). Pergeseran perhatian dari organisasi ke target-target yang lain mencerminkan evolusi alami tentang konstruk komitmen, yaitu dari konsep umum yang berkaitan dengan tujuan dan nilai organisasi, ke pemilik tujuan dan nilai yang lebih spesifik sebagai target komitmen ganda (Reichers, 1985). Pendekatan ini lebih realistik mencerminkan sifat keterikatan karyawan-organisasi sebagai individu yang mengalaminya.

Dari berbagai foci komitmen yang telah diidentifikasi, komitmen pada supervisor semakin mendapat perhatian dari peneliti beberapa tahun terakhir (Wong et al., 2002). Supervisor sebagai salah satu foci komitmen merupakan foci terdekat (proximal foci) bagi karyawan, secara psikologis mempunyai efek kuat pada sikap dan perilaku karyawan. Apalagi supervisor berfungsi sebagai pengatur imbalan bagi bawahannya (Farh et al., dalam Chen et al., 2002). Dengan fungsinya itu dapat menimbulkan persepsi karyawan yang berkaitan dengan keadilan prosedural dan keadilan distribusi. Tindakan supervisor dalam melaksanakan tugas sehari-harinya akan memengaruhi persepsi karyawan tentang hal itu. Seberapa jauh persepsi karyawan tentang perlakuan keadilan prosedural dan distributif akan memengaruhi sikap kerja karyawan, yaitu komitmennya pada supervisor.

\section{Keadilan Prosedural dan Keadilan Distributif}

Menurut Cohen dalam Pinder (1998), keadilan (justice) adalah pikiran yang muncul ketika orang menerima sesuatu yang mereka dan orang-orang di sekitarnya berhak mendapatkannya. Sesuatu yang dapat diterima ini dapat berupa manfaat (seperti kenaikan gaji) atau yang menyusahkan (seperti pindah ke kota atau daerah lain yang tidak diinginkan), atau juga outcome yang sifatnya non-moneter seperti prestis, status dan tanggungjawab (Greenberg, 1990). Orang akan peduli tidak hanya pada apa yang mereka terima melainkan juga peduli pada apa yang diterima oleh orang lain.

Teori keadilan menyatakan bahwa individu mendefinisikan keadilan tidak hanya menurut outcome yang diterima tetapi juga menurut prosedur yang digunakan untuk menentukan outcome seseorang, yang disebut dengan keadilan prosedural (Levental et al. dalam Skarlicki \& Folger, 1997). Ini mengarah pada pengertian bahwa keadilan dapat dikategorikan menjadi keadilan yang berfokus pada isi (keadilan distributif) dan keadilan yang berfokus pada proses (keadilan prosedural) (Greenberg, 1990). 
Keadilan distributif berkaitan dengan persepsi karyawan terhadap outcome yang diterima. Keadilan prosedural berkaitan dengan persepsi karyawan terhadap kebijakan dan prosedur yang digunakan dalam menentukan outcome (Skarlicki \& Folger, 1997; Colquitt, 2001). Dengan demikian, Individu dalam usahanya memenuhi rasa keadilan di tempat kerja, outcome yang mereka terima saja ternyata tidak cukup. Mereka menaruh perhatian pada cara atau prosedur tentang bagaimana outcome tersebut ditetapkan.

Dasar konseptual keadilan distribusi berasal dari teori keadilan Adam tahun 1965 (Colquitt \& Jackson, 2006). Teori itu menyatakan bahwa orang akan membandingkan rasio outcome terhadap inputnya dengan rasio outcome terhadap input orang lain. Apabila perbandingan tersebut ternyata tidak sama, pihak yang memiliki rasio lebih tinggi akan merasa bersalah karena dibayar terlalu tinggi, sementara pihak yang memiliki rasio lebih rendah merasa marah karena dibayar lebih rendah. Berdasarkan pernyataan itu orang beranggapan bahwa pembayaran yang lebih tinggi atau lebih rendah sama-sama menimbulkan rasa ketidakadilan.

Perkembangan selanjutnya perhatian mengarah pada keadilan yang lebih berorientasi proses. Perkembangan ini muncul karena tumbuhnya rasa ingin tahu untuk mendapatkan outcome yang adil. Ini berarti setelah perhatian diarahkan pada apa keputusan itu (outcome), berkembang pada bagaimana keputusan itu dibuat (prosedur). Thibaut dan Walker dalam Greenberg (1990) lebih menggunakan terminologi "kontrol keputusan" kaitannya dengan keadilan distributif, dan "kontrol proses" kaitannya dengan keadilan prosedural. Mengenai hubungan antara keadilan dan komitmen, Tang dan SarsfieldBaldwin (1996) menyatakan bahwa bila karyawan dapat dijamin dengan perlakuan prosedural yang adil, mereka cenderung menjadi lebih loyal, yang merupakan tanda dari komitmen. Bila keadilan prosedural terwujud, maka lebih sulit untuk mempertanyakan outcome (keadilan distributif). Penelitian mereka menemukan bahwa keadilan distributif dan prosedural merupakan prediktor penting bagi komitmen. Namun demikian, sekalipun keadilan distributif dan prosedural adalah penting dan dikaitkan dengan sikap dan perilaku kerja, bukti akhir-akhir ini menunjukkan bahwa keadilan prosedural merupakan prediktor yang lebih baik bagi komitmen karyawan dibanding keadilan distributif (Folger \& Konovsky dalam Meyer \& Smith, 2000, Barling \& Philips dalam Witt, Kacmar, \& Andrews, 2001; Nasurdin \& Ahmad, 2000). Uraian tersebut menunjukkan adanya hubungan positif antara keadilan dan sikap kerja, yaitu komitmen.

Tindakan supervisor dalam melaksanakan fungsinya sehari-harinya akan memengaruhi persepsi karyawan tentang keadilan prosedural dan keadilan distributif. Baik keadilan prosedural maupun keadilan distributif, keduanya merupakan sinyal status atau perhatian supervisor pada bawahannya. Untuk keadilan distributif, tidak hanya mengandung elemen materi tetapi juga elemen hubungan (Lee et al., 2000). Kemudian persepsi karyawan tentang keadilan ini digunakan oleh karyawan untuk menilai atasannya/supervisor. Dengan perkataan lain, seberapa jauh persepsi karyawan tentang perlakuan keadilan prosedural dan distributif akan memengaruhi komitmennya pada supervisor.

Hipotesis 1: Keadilan prosedural dan keadilan distributif mempunyai pengaruh positif terhadap komitmen karyawan pada supervisor.

Jarak Kekuasaan

Begitu besar perhatian ditujukan pada isu budaya karena budaya organisasional mempunyai efek signifikan pada bagaimana karyawan memandang tanggungjawabnya pada organisasi dan pada komitmennya (Chen, 2004).

Rerangka teoretikal Hofstede membagi budaya ke dalam lima dimensi, yaitu individualisme, jarak kekuasaan, penghindaran terhadap ketidakpastian, maskulinitas, dan orientasi jangka panjang. Secara singkat, individualisme mengacu pada pentingnya otonomi individual. 
Jarak kekuasaan mengacu pada sejauhmana kekuasaan yang tidak merata diterima, atau sejauhmana anggota organisasi yang kurang berkuasa (less powerful) menerima bahwa kekuasaan terdistribusi secara tidak sama. Penghindaran terhadap ketidakpastian mengacu pada sejauhmana ketidakpastian dihindari sebagai suatu ancaman, dan maskulinitas mengacu pada sekumpulan nilai yang berkaitan dengan capaian dan tantangan (More et. al., 1995).

Di antara lima dimensi di atas, dimensi yang akan dibahas lebih lanjut dalam penelitian ini adalah dimensi jarak kekuasaan. Pertimbangannya adalah bahwa hubungan atasanbawahan selama ini telah menjadi fokus diskusi dan investigasi. Kekuasaan merupakan inti (core) dari hubungan superior-bawahan (Afza, 2005). Dalam setting organisasi supervisor menggunakan kekuasaan agar bawahan melakukan apa yang diharapkan. Jarak kekuasaan berkaitan dengan angan-angan tentang apa yang dapat diterima dalam hubungan atasan-bawahan. Oleh karena itu jarak kekuasaan menjadi relevan dengan persepsi karyawan tentang perlakuan adil yang dilakukan oleh supervisornya (Lee et al., 2000).

Selama ini masyarakat Indonesia dikenal sebagai masyarakat yang termasuk dalam dimensi budaya jarak kekuasaan tinggi (Hofstede, 2005), namun variabilitas dimensi budaya dalam negara sangat dimungkinkan (Cross \& Madson dalam Clugston et al., 2000; Morrison, Chen, \& Salgado, 2004), sehingga variabilitas budaya di tempat kerja juga dapat terjadi. Persepsi kultural bervariasi antar dan dalam negara (Clugston et al., 2000), dan reaksi individual terhadap budayanya dapat berbeda-beda (Swaidan \& Hayes, 2005), dapat bereaksi dalam cara yang baru, kreatif, destruktif, atau dalam cara yang tidak diharapkan (Hofstede, 2005).

Secara umum organisasi dengan budaya jarak kekuasaan rendah, menunjukkan perbedaan dalam hubungan antara atasan-bawahan dengan organisasi dengan jarak kekuasaan tinggi. Sekalipun demikian variabilitas di tempat kerja itu sendiri sangat dimungkinkan. Sindroma kultural yang lebih mendasar seperti keyakinan, norma, dan nilai yang mencerminkan dimensi kultural makro juga analog dengan individual (Triandis dalam Clugston et al., 2000). Dari sudut pandang operasional studi budaya dalam Negara memerlukan instrumen pengukuran yang menyerap persepsi budaya individual (Triandis dalam Clugston et al., 2000). Oleh karena itu dalam penelitian ini akan menyelidiki variabilitas tersebut, dengan individu karyawan sebagai unit analisis.

Selanjutnya karyawan dengan jarak kekuasaan tinggi, hubungan antara atasan-bawahan bersifat hirarkikal sehingga akan tergantung pada supervisor, dan akan membentuk keterikatan patuh pada supervisor. Kedekatan dan interaksi yang teratur dengan karyawan, supervisor menjadi lebih efektif dalam memonitor, memberi penghargaan, dan mempengaruhi sikap dan perilaku karyawan dibanding organisasi/perusahaan (Becker et al., 1996; Becker \& Kernan, 2003).

Sebaliknya karyawan dengan jarak kekuasaan rendah cenderung tidak menggambarkan ketergantungan pada supervisor, sehingga tidak membentuk keterikatan patuh pada supervisor. Hubungan antara bawahan-atasan lebih bersifat pragmatis, egaliter dan pekerjaan mereka mempunyai status yang sama, supervisinya berdasarkan pengalaman, dan bawahan berharap untuk diajak berunding, dan tidak mengandalkan superior dan aturan formal (Hofstede, 2005). Dengan perkataan lain, karyawan dengan jarak kekuasaan rendah menyukai kebebasan atau keleluasaan, egalitarian, dan tidak menyukai supervisi ketat (oversupervision) (Hofstede dalam Palich et al., 1995). Di samping itu, mereka juga lebih menghargai pengaruh yang bersifat tidak memaksa (noncoercive influence), seperti misalnya kekuasaan imbalan dan pakar (Palich et al., 1995).

Kaitannya dengan keadilan yang dipersepsikan, karyawan dengan jarak kekuasaan tinggi kurang sensitif terhadap keadilan prosedural dan distributif, karena mereka meyakini bahwa ketidakadilan yang terjadi mencerminkan legitimasi dari ketidaksamaan kekuasaan antara 
supervisor dan bawahan (Lee et al., 2000), yang memang sudah mereka terima. Sebaliknya, bagi karyawan dengan jarak kekuasaan rendah lebih peduli dengan keadilan yang dialami. Hal ini terjadi karena mereka merasa hubungannya dengan supervisor bersifat egaliter dan pekerjaan mereka mempunyai status yang sama, segala sesuatu dapat dirundingkan, dan tidak mengandalkan superior dan aturan formal. Ketidakadilan yang terjadi tidak bisa diterima begitu saja, dan akan membentuk persepsi tentang ketidakadilan. Bagaimana persepsi keadilan/ketidakadilan dievaluasi akan memengaruhi besaran dampak dari keadilan/ketidakadilan ini (Yang et al., 2004). Keyakinan normatif tentang keadilan akan bervariasi menurut nilai kultural (jarak kekuasaan) yang dianut (Tyler \& McGraw, 1986). Dengan demikian pengaruh persepsi karyawan tentang keadilan pada komitmen pada supervisor tergantung pada jarak kekuasaan yang dirasakan karyawan. Secara lebih spesifik penelitian Lee et al., (2000) menghasilkan temuan bahwa hubungan antara keadilan prosedural dan keadilan distributif dan evaluasinya terhadap atasan lebih tinggi bagi karyawan dengan orientasi jarak kekuasaan rendah. Secara implisit temuan ini menyiratkan adanya peran moderasi jarak kekuasaan pada hubungan antara keadilan prosedural dan keadilan distributif dan outcome kerja (Yang et al., 2004).

Hipotesis 2: Jarak kekuasaan memoderasi pengaruh keadilan prosedural dan keadilan distributif terhadap komitmen pada supervisor.

\section{KERANGKA PEMIKIRAN}

Persepsi karyawan akan keadilan prosedural dan keadilan distributif akan berpengaruh pada sikap kerjanya dan evaluasinya pada supervisor. Keadilan prosedural maupun keadilan distributif yang mereka persepsikan, merupakan sinyal status atau perhatian supervisor pada bawahannya. Namun pengaruh tersebut bervariasi tergantung pada tinggi rendahnya orientasi jarak kekuasaan yang dipersepsikan oleh karyawan.

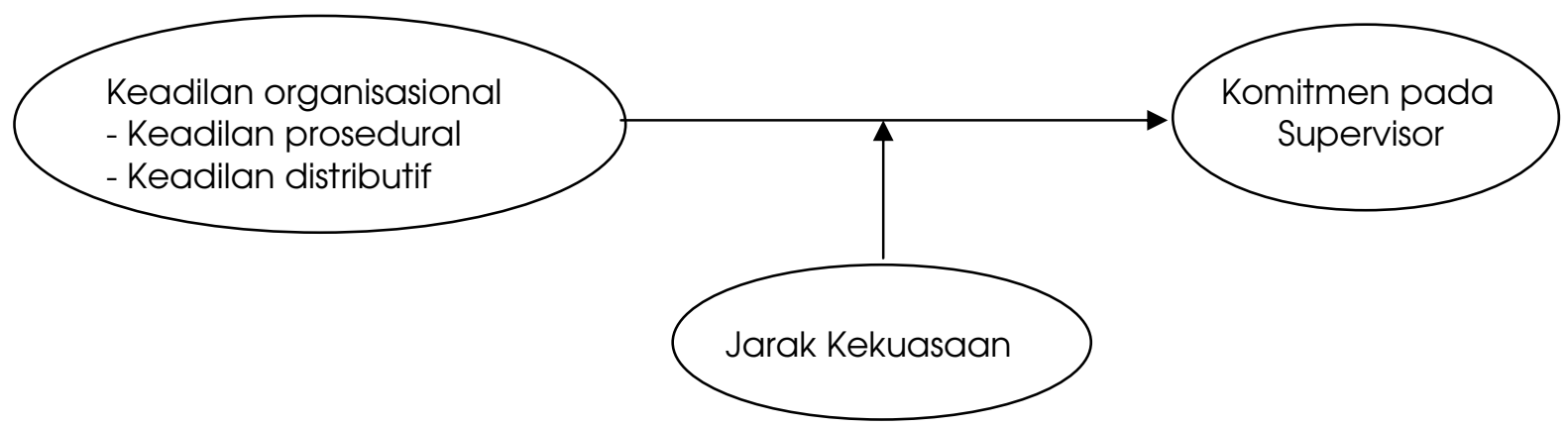

Gambar 1.

Hubungan antara keadilan organisasional, komitmen

pada supervisor dan jarak kekuasaan

\section{METODE PENELITIAN}

Populasi, Sampel, dan Prosedur Pengumpulan Data

Populasi dalam studi ini adalah karyawan administrasi di salah satu perusahaan batik terbesar di Surakarta. Sampel sebesar 150 orang karyawan. Prosedur pengambilan sampelnya dilakukan melalui supervisor karyawan masing-masing karyawan untuk mendapatkan daftar karyawan yang menjadi bawahannya. Setelah itu diambil sampel secara random sejumlah yang diperlukan. Data dikumpulkan dengan menyebarkan kuesioner melalui supervisor sebagai atasan langsung masing-masing karyawan. 
Pengukuran

Semua variabel diukur dengan skala Likert 5 -item yang dimulai dengan skala $1=$ sangat tidak setuju, sampai dengan skala 5 = sangat setuju.

Komitmen pada supervisor diukur dengan 17-item dari Chen et al. (2002). Misalnya, saya berusaha memberi yang terbaik atas tugas yang diberikan oleh supervisor. Keadilan prosedural diukur dengan 7-item dari Thibaut dan Walker (1975) dan Leventhal (1980). Keadilan distributif diukur dengan 4-item dari Leventhal (1980). Jarak kekuasaan diukur dengan 6-item skala kultural dari Dorfman dan Howel (1988) sebagaimana digunakan oleh Clugston et al. (2000). Kepada semua instrumen pengukuran variabel tersebut dilakukan uji validitas dan reliabilitas, dan hasilnya semuanya dinyatakan valid dan reliabel.

\section{HASIL DAN PEMBAHASAN}

Hasil analisis deskriptif menunjukkn bahwa rata-rata karyawan mempunyai tingkat komitmen pada supervisor relatif tinggi (skor minimum $=27$, skor maksimum $=85$, dan skor rata-rata 59,37 ). Tingkat keadilan prosedural relatif tinggi (skor minimum $=7$, skor maksimum $=35$, dan skor rata-rata 25,76). Tingkat keadilan distributif relatif tinggi (skor minimum $=7$, skor maksimum $=20$, dan skor rata-rata 16,45). Sedang tingkat orientasi jarak kekuasaan juga relatif tinggi (skor minimum $=6$, skor maksimum $=30$, median $=15$, dan skor rata-rata 15,25 ). Artinya sebagian besar karyawan menerima distribusi kekuasaan yang tidak merata.

Uji hipotesis dilakukan dengan Analisis Regresi Moderasian. Hasil analisis regresi untuk keadilan prosedural dan keadilan distributif dengan komitmen pada supervisor diperoleh hasil bahwa baik keadilan prosedural maupun keadilan distributif secara signifikan $(<0,05)$ berpengaruh positif pada komitmen karyawan pada supervisor. Artinya semakin tinggi keadilan prosedural yang dipersepsikan oleh karyawan perusahaan batik, semakin tinggi pula komitmennya pada supervisor sepanjang keadilan distributifnya tetap. Selanjutnya, semakin tinggi keadilan distributif yang dipersepsikan oleh karyawan peruahaan batik semakin tinggi pula komitmen karyawan pada supervisor, sepanjang keadilan proseduralnya tetap. Berdasarkan penjelasan tersebut maka hipotesis 1 yang menyatakan bahwa keadilan prosedural dan keadilan distributif berpengaruh positif pada komitmen karyawan pada supervisor didukung.

Temuan ini sesuai dengan hasil studi Tang dan Sarsfield-Baldwin (1996) yang menyatakan bahwa keadilan distributif dan prosedural merupakan prediktor penting bagi komitmen.

Kemudian, hasil analisis regresi moderasian menunjukkan adanya efek interaksi (interaction effect) variabel keadilan prosedural, keadilan distributif dan jarak kekuasaan terhadap komitmen karyawan pada supervisor. Untuk menjelaskan pernyataan ini perlu melihat persamaan regresi moderasian sebagai berikut.

$$
Y=33,288+0,476 X_{1}+0,978 X_{2}-0,892 X_{3}
$$

Maksud persamaan tersebut adalah:

Koefisien regresi $X_{3}$ (interaksi $X_{1} X_{2}$ ) bertanda negatif dan nilai signifikansinya sebesar 0,001 , artinya keadilan prosedural dan jarak kekuasaan secara signifikan mempunyai efek interaksi negatif terhadap komitmen karyawan pada supervisor dengan tingkat signifikansi sebesar 1\%. Artinya pengaruh keadilan prosedural terhadap komitmen karyawan pada supervisor akan lebih negatif dengan semakin tingginya jarak kekuasaan yang dipersepsikan oleh karyawan.

Selanjutnya, hasil analisis regresi moderasian untuk keadilan distributif, komitmen karyawan pada supervisor, dengan jarak kekuasaan sebagai variabel moderator dihasilkan persamaan regresi moderasian sebagai berikut. 


$$
Y=29,292+0,527 X_{1}+1,122 X_{2}-1,098 X_{3}
$$

Maksud persamaan tersebut adalah:

Koefisien regresi $X_{3}$ bertanda negatif dan nilai signifikansinya sebesar 0,000 , artinya keadilan distributif dan jarak kekuasaan secara signifikan mempunyai efek interaksi negatif terhadap komitmen karyawan pada supervisor dengan tingkat signifikansi sebesar 1\%. Artinya pengaruh keadilan distributif terhadap komitmen karyawan pada supervisor akan lebih negatif dengan semakin tingginya jarak kekuasaan yang dipersepsikan oleh karyawan.

Berdasarkan penjelasan tersebut maka hipotesis 2 yang berbunyi jarak kekuasaan memoderasi pengaruh keadilan prosedural dan keadilan distributif terhadap komitmen pada supervisor, didukung.

Temuan ini mendukung temuan sebelumnya (Lee et al., 2000), yaitu bahwa hubungan antara keadilan prosedural dan keadilan distributif dan evaluasinya terhadap atasan lebih tinggi bagi karyawan dengan orientasi jarak kekuasaan rendah. Sementara bagi karyawan dengan jarak kekuasaan tinggi kurang sensitif dengan rasa keadilan, karena ketidakadilan yang terjadi merupakan legitimasi dari tidak meratanya distribusi kekuasaan. Oleh karena itu, dengan semakin tingginya jarak kekuasaan yang dipersepsikan maka pengaruh keadilan pada komitmen justru negatif.

Koefisien determinasi atau Nilai $R^{2}$ (Adjusted $R$ Square) digunakan untuk mengetahui kemampuan variabel independen dalam menjelaskan variasi perubahan variabel dependen. Nilai R2 (Adjusted R Square) naik dari sebesar 0,117 atau sebesar 11,7\%, menjadi sebesar 178 atau sebesar 17,8\%, untuk keadilan prosedural; dan dari sebesar 0,103 atau sebesar $10,3 \%$ naik menjadi sebesar 0,177 atau sebesar 17,7\% untuk keadilan distributif ketika interaksi antara keadilan prosedural dan keadilan distributif terjadi. Kenaikan nilai $R^{2}$ ini menunjukkan adanya peningkatan kemampuan variabel keadilan prosedural dan jarak kekuasaan dalam menjelaskan variasi perubahan variabel komitmen karyawan pada supervisor ketika karyawan juga mempertimbangkan persepsinya terhadap orientasi jarak kekuasaan.

\section{SIMPULAN DAN SARAN}

Simpulan

Hasil analisis regresi moderasian menunjukkan bahwa jarak kekuasaan memoderasi pengaruh keadilan prosedural dan keadilan distributif yang dipersepsikan oleh karyawan terhadap komitmen karyawan pada supervisor. Hasil ini dapat diketahui berdasarkan diperolehnya koefisien interaksi $\left(b_{3}\right)$ yang signifikan maupun melalui kenaikan koefisien determinasi ( $\left.R^{2}\right)$.

Kemudian diperoleh nilai $R^{2}$ (Adjusted $R$ Square) dalam regresi moderasian tentang pengaruh keadilan prosedural terhadap komitmen karyawan pada supervisor, dengan jarak kekuasaan sebagai variabel moderator diperoleh nilai R2 sebesar 178 atau sebesar $17,8 \%$. Ini berarti kemampuan variabel keadilan prosedural dan jarak kekuasaan dalam menjelaskan variasi perubahan variabel komitmen karyawan pada supervisor adalah sebesar $17,8 \%$. Demikian juga dengan nilai $R^{2}$ (Adjusted $R$ Square) dalam regresi moderasian tentang pengaruh keadilan distributif terhadap komitmen karyawan pada supervisor, dengan jarak kekuasaan sebagai variabel moderator diperoleh nilai R2 0,177 atau sebesar 17,7\%. Ini berarti kemampuan variabel keadilan distributif dan jarak kekuasaan dalam menjelaskan variasi perubahan variabel komitmen karyawan pada supervisor adalah sebesar 17,8\%.

Saran 
Penelitian sebelumnya yang dilakukan di perusahaan yang sama dengan judul "Komitmen Karyawan pada Organisasi dan Komitmen Karyawan pada Supervisor: Implikasinya pada Kinerja," telah menghasilkan temuan bahwa komitmen pada supervisor mempunyai hubungan lebih kuat dengan kinerja tugas dibanding komitmen pada organisasi (Sawitri \& Karsono, 2006). Atas temuan tersebut maka dilakukan penelitian lanjutan ini, untuk lebih mengeksplorasi variabel yang mempengaruhi komitmen karyawan pada supervisor. Berdasarkan simpulan yang telah dijelaskan maka disarankan kepada persahaan batik bahwa untuk meningkatkan komitmen karyawan pada supervisor perlu mempertimbangkan rasa keadilan prosedural dan keadilan distributif karyawan. Misalnya, tentang prosedur yang digunakan untuk menentukan besarnya kompensasi perlu dilakukan secara transparan, konsisten, serta memberi kesempatan pada karyawan untuk menanyakannya. Demikian juga dengan besaran kompensasi yang diberikan kepada karyawan apakah memang sudah sesuai dengan pengorbanan karyawan.

Pengaruh rasa keadilan prosedural dan keadilan distributif terhadap peningkatan komitmen karyawan pada supervisor tersebut ternyata akan menjadi lebih positif bagi karyawan dengan jarak kekuasaan rendah dan menjadi negatif bagi karyawan dengan jarak kekuasaan tinggi. Oleh karena itu agar menjadi lebih efektif usaha peningkatan komitmen karyawan pada supervisor, hendaknya perusahaan mempertimbangkan tinggi rendahnya jarak kekuasaan ini. Misalnya, bagaimana perusahaan mengolah persepsi karyawan agar mereka mempunyai persepsi jarak kekuasaan rendah, yaitu karyawan tidak mempunyai persepsi (atau setidaknya mengurangi persepsi) bahwa kekuasaan antara atasan-bawahan terdistribusi secara tidak merata.

Saran yang lain adalah diharapkan peneliti lain menjadi tertarik untuk melakukan penelitian sejenis di bidang yang lain selain di perusahaan manufaktur bidang tekstil untuk kepentingan generalisasi. Hal ini sekaligus merupakan keterbatasan penelitian ini, yang hanya dilakukan pada satu perusahaan tekstil.

\section{DAFTAR PUSTAKA}

Al-Meer, A. R. A. (1989). Organizational Commitment: A Comparison of Westerners, Asians, and Saudis. International Studies of Management \& Organization, 19, 74-84.

Afza, M. (2005). Superior-Subordinate Relationships and Satisfaction in Indian Small Business Enterprises. Vikalpa, 30: 11-19

Azwar, S. (2006). Reliabilitas dan Validitas. Pustaka Pelajar. Yogyakarta.

Becker, T. E. (1992). Foci and Bases of Commitment: Are They Distinctions Worth Making? Academy of Management Journal, 35: 232.

Bochner, S., \& Hesketh, B. (1994). Power Distance, Individualism/Collectivism, and JobRelated Attitude in a Cultural Diverse Work Group. Journal of Cross-Cultural Psychology, 25: 233-257.

Becker, T. E., Billings, R. S., Eveleth, D. M., \& Gilbert, N. L. (1996). Foci and Bases of Employee Commitment: Implications for Job Performance. Academy of Management Journal, 39:464-482.

Bishop, J. W. \& Scott, K. D. (1996). Multiple Foci of Commitment in a Work Team Environment. Academy of Management Proceedings, 269-273.

Becker, T. E., \& Kernan, M. C. (2003). Matching Commitment to Supervisors and Organizations to In-Role and Extra-Role Performance. Human Performance, 16(4), 327-348.

Clugston, M., Howell, J. P., \& Dorfman, P. W. (2000). Does Cultural Socialization Predict Multiple Bases and Foci of Commitment? Journal of Management. 26: 5-30. 
Colquitt, J. A. (2001). On the Dimensionality of Organizational Justice: A Construct Validation of a Measure. Journal of Applied Psychology. 86: 386-400.

Colquitt, J. A., Conlon, D. E., Wesson, M. J. \& Porter C. O. L. H., \& Yee Ng, K. (2001). Justice at the Millennium: A Meta-Analytic Review of 25 Years of Organizational Justice Research. Journal of Applied Psychology, 86: 425-445.

Chen, Z. X., Tsui, A. S., \& Farh, J. L. (2002). Loyalty to supervisor vs. organizational commitment: Relationships to employee performance in China. Journal of Occupational and Organizational Psychology, 75: 339-356.

Chen, L. Y. (2004) Examining the Effect of Organization Culture and Leadership Behaviors on Organizational Commitment, Job Satisfaction, and Job Performance at Small and Middle-sized firms of Taiwan. The Journal of American Academy of Business, 432-438.

Colquitt, J. A., \& Jackson, C. L. (2006). Justice in Teams: The Context Sensitivity of Justice Rules Across Individual and Team Contexts. Journal of Applied Social Psychology, 36: 868899.

Greenberg, J. 1990. Organizational Justice: Yesterday, Today, and Tomorrow. Journal of Management, 16: 399-432.

Hartono, J. (2004/2005). Metodologi Penelitian Bisnis. Yogyakarta: BPFE.

Hofstede, G. \& Hofstede, G.J (2005). Cultures and Organizations Software of the Mind. Revised and Expanded 2nd Edition. New York: McGraw-Hill, Inc.

Kerlinger, F. N. (1979). Behavioral Research: A Conceptual Approach. New York: Holt, Rinehart and Winston.

Luthans, F. (1995). Organizational Behavior. McGraw-Hill, Inc., New York.

Lu, L. T. \& Lee, Y. H. (2005). The Effect of Culture on the Management Style and Performance of International Joint Venture in China: The Perspective of Foreign Parent Firms. International Journal of Management, 22: 452-462

McGee, G. W. \& Ford, R. C. (1987). Two (or More?) Dimensions of Organizational Commitment: Reexamination of the Affective and Continuance Commitment Scales. Journal of Applied Psychology, 69 : 638-642.

Meyer, J. P., Paunonen, S. V., Gellaty, I. R., Goffin, R. D., \& Jackson, D. N. (1989). Organizational Commitment and Job Performance: It's the Nature of the Commitment That Counts. Journal of Applied Psychology, 74: 152-156.

Meyer, J. P., \& Allen, N. J., \& Smith, C. A. (1993). Commitment to Organizations and Occupations: Extension and Test of a Three-Component Conceptualization. Journal of Applied Psychology,78: 538-551.

More, P. H. B., Wong, G. Y. Y., \& Olve, N. G. (1995). Acquisition of Managerial Values in The People's Republic of China and Hong Kong. Journal of Cross-Cultural Psychology, 26: 255-275.

Meyer, J. P., \& Smith, C. A. (2000). HRM practice and organizational commitment: Test of a mediation model. Canadian Journal of administrative sciences, 17: 319-331.

Morrison, E. W., Chen, Y. R., \& Salgado, S. R. (2004). Cultural Differences in Newcomer Feedback Seeking: A Comparison of the United State and Hongkong. Applied Psychology: An International Review, 53: 1-22.

McGinnis, M. A. (2005). Lessons in Cross-Cultural Negotiations. Supply Chain Management Review, 9-10.

McCoy, S., Galletta, D. F., \& King, W. R. (2005). Integrating National Culture into IS Research: The Need For Current Individual-Level Measures. Communications of the Association for Information Systems, 15: 211-224. 
Nasrudin, A. M., \& Ahmad, Z. A. (2000). Does Gender Moderate The Effect of Procedural Justice on Organizational Commitment Among Malaysian Employees? School of Management, Universiti Sains Malaysia. Sumber di ProQuest masih dalam pencarian.

Palich, L. E., Hom, P. W., \& Griffeth, R. W. (1995). Managing in The International Context: Testing Cultural Generality of Sources of Commitment to Multinational Enterprises. Journal of Management, 21: 671-690.

Pinder, C. C. (1998). Work Motivation in Organizational Behavior. New Yersey: Prentice Hall, Uper Saddle River.

Reichers, A. E. (1985). A Review and Reconceptualization of Organizational Commitment. Academy of Management Review, 10: 465-476.

(1986). Conflict and Organizational Commitments. Journal of Applied Psychology, 71: 508-514.

Robbin, Stephen P. (2005). Organizational Behavior. New Jersey: Prentice-Hall, Inc.

Sekaran, U. (1992). Research Methods for Business: A Skill Building Approach. New York: John Wiley \& Sons. Inc.

Smith, P. B., Dugan, S., \& Trompenaars, F. (1996). National Culture and The values of Organizational Employees: A Dimensional Analysis Across 43 Nations. Journal of CrossCultural Psychology, 27: 231-264.

Skarlicki, D. P., \& Folger, R. (1997). Retaliation in the Workplace: The Roles of Distributive, Procedural, and Interactional Justice. Journal of Applied Psychology, 82: 434-443.

Somers, M. J., \& Birnbaum D. (1998). Work-related commitment and job performance: it's also the nature of the performance that counts. Journal of Organizational Behavior, 19: 621634.

Suliman, A., \& lles, P. (2000). Is continuance commitment beneficial to organizational? Commitment-performance relationship: a new look. Journal of Managerial Psychology, 15: 407-426.

Sawitri, H. S. R., \& Karsono (2006). Komitmen Karyawan pada organisasi dan Komitmen Karyawan pada Supervisor: Implikasinya pada Kinerja. Jurusan Manajemen Universitas Sebelas Maret Surakarta.

Supranto, J. (2004). Analisis Multivariat: Arti \& Iterpretasi. Rineka Cipta. Jakarta.

Swaidan, Z., \& Hayes, L. A. (2005). Hofstede Theory and Cross Cultural Ethics Conceptualization, Review, and Research Agenda. The Journal of American Academy of Business, 10-15.

Tyler, T. R. (1994). Psychological Models of the Justice Motive: Antecedents of Distributive and Procedural Justice. Journal of Personality and Social Psychology, 6: 850-863.

Tyler, T. R., \& McGraw, K. M. (1986). Ideology and interpretation of personal experience: procedural justice and political quiescence. Journal of Social Issues, 42: 115-128.

Tang, T. L., \& Sarfield-Baldwin, L. J. (1996). Distributive justice and procedural justice as related to satisfaction and commitment. S. A. M Advanced Management Journal, 61: 25.

Wiener, Y. (1982). Commitment in organizations: A Normative View. Academy of Management Review, 7(3), 418-428.

Witt, L. A., Kacmar, K. M. \& Andrews, M. C. (2001). The interactive effect of procedural justice and exchange ideology on supervisor-rated commitment. Journal of Organizational Behavior, 22: 505-515.

Wong, Y. T., Wong, C. S., \& Ngo, H. Y. (2002). Loyalty to Supervisor and Trust in Supervisor of Workers in Chinese Joint Ventures: A Test of Two Competing Models. International Journal of Human Resource Management, 13: 883-900. 
Yousef, D. A. (2000). Organizational commitment: a mediator of the relationship of leadership behavior with job satisfaction and performance in a non-western country. Journal of Management Psychology, 15: 6-24.

Yang, J., Peng, T. K., \& Mossholder, K. W. (2004). Procedural Justice Climate and Group Power Distance Orientation: A Case of Cross-Level Effects. Academy of Management Best Conference Paper 2004 OB: E1-E6. 